\title{
DOS ATOS DE COMÉRCIO À TEORIA DA EMPRESA: UMA ABORDAGEM TEÓRICA
}

\author{
Alexandre de Mendonça Nascimento ${ }^{1}$, Carla Bonomo $^{1}$, Pedro Teófilo de Sá ${ }^{2}$ \\ ${ }^{1}$ Universidade Estadual de Londrina - UEL. Curso de Direito, Londrina - PR. ${ }^{2}$ Universidade do Oeste Paulista - \\ UNOESTE. Curso de Direito, Presidente Prudente - SP. E-mail: ale_nmb@hotmail.com
}

\begin{abstract}
RESUMO
O presente trabalho tem como objetivo geral estudar os atos de comércio, e como objetivo específico analisar o seu desenvolvimento numa abordagem teórica para chegar ao tratamento do atual Código Civil (teoria da empresa). O sistema liberal Francês, apoiado no Código Napoleônico, deu origem aos atos de comércio, caracterizando tais atos e não o comerciante, pois não considerava o sujeito, mas sim, o objeto negocial desenvolvido. O Código Comercial brasileiro de 1850 também silenciou com relação à definição. No entanto, logo depois, na Itália surgiu a teoria da empresa que contribuiu para diminuir a celeuma, tendo sido adotada pelo Código Civil brasileiro de 2002, no seu art. 966, quando definiu a figura do empresário.
\end{abstract}

Palavras-chave: Atos de comércio, empresa e empresário.

\section{FROM COMMERCIAL ACTS TO THEORY OF THE FIRMS: A THEORETICAL APPROACH}

\begin{abstract}
This present work seeks to study, as general objective, the commercial acts; as specific objective, analysis its development to understand the current Brazilian Civil Code( theory of the firms). The French liberal system, based on Napoleon's Code, gave birth to the commercial acts, considering not the subject, person, but the bargaining object. The Brazilian Code from 1850 also adopted the commercial acts. In 1942, in Italy, rises the theory of the firms, defining what is a firm, and not simply what is its object. This last theory was the one adopted in the current Brazilian Civil Code, on its article 966, characterizing the figure of the entrepreneur.
\end{abstract}

Keywords: commercial acts, enterprise, entrepreneur. 


\section{INTRODUÇÃO E OBJETIVO}

$\mathrm{Na}$ antiguidade os atos de comércio eram os caracterizadores da mercantilidade dos negócios realizados pelos mercadores. Eles têm origem na França, com o Código Napoleônico, no auge do liberalismo. Filho desta ideologia, o Código disciplinava que qualquer pessoa que realizasse atividade comercial prevista na lei seria considerada comerciante. Desta maneira, o comerciante se caracteriza como tal não enquanto sujeito, mas sim pelo objeto de seu negócio que era desenvolvido. (Ulhoa,2014, p.27)

A partir do Código Napoleônico de 1807, diversos países passam a reger o Direito Comercial baseando-se nos atos de comércio, disciplinando em seus Códigos. A doutrina nunca conseguiu elaborar um conceito científico do que seriam tais atos, tanto que o Professor da Faculdade de Direito de São Paulo, Brasílio Machado, sintetizou ser: "Problema insolúvel para a doutrina, martírio para o legislador, enigma para a jurisprudência."(REQUIÃO, 2007, p.36)

Se impossível era estabelecer uma diferença entre tais atos e atos civis, como diferenciar um sujeito civil de um comerciante? Sem dúvidas os Códigos não seriam capazes de enumerar, taxativamente, atos comerciais, um por um, visto que o comércio não e resultado de uma ação estática, mas sim se reveste de atos mutantes e sempre se renova e se amplia. Além disso, como já dito anteriormente, era o objeto da ação, e não a ação em si, que definia o comerciante.

Segundo Requião (2008, p.40), tendo em vista os conflitos surgidos pela enumeração do Código de 1807, na França, enumeração esta que não era exaustiva, o Código Comercial brasileiro de 1850 silenciou-se propositalmente sobre a conceituação dos atos comerciais, pois se preocupou em definir o comerciante.

O Código Civil de 2002, no tocante ao direito de empresa, também não trilhou caminho diferente, tratando da figura do empresário no artigo 966.

Partindo dessa visão noção dos atos de comércio, e do tratamento dado pelos códigos é que se faz necessário o estudo acerca do tema. Portanto, o presente trabalho tem como objetivo geral Estudar os atos de comércio, e coo objetivo específico analisar o seu desenvolvimento numa abordagem teórica para chegar ao tratamento do atual Código Civil.

\section{METODOLOGIA}

O trabalho vale-se da metodologia histórica, e tem como instrumento de coleta de dados para a sua realização, a pesquisa bibliográfica pautada em doutrinas, artigos científicos, revistas especializadas e sites jurídicos. 


\section{RESULTADOS}

A evolução dos atos de comércio, apoiados na teoria da empresa, surgida na Itália, contribuíram decisivamente para a nova visão sobre o empresário, modernamente caracterizado no artigo 966 do Código Civil brasileiro de 2002, ao definir o sujeito se apoiou na identificação da figura da mercancia com profissionalismo, no exercício de atividade econômica organizada de produção ou circulação de bens ou serviços.

A teoria da empresa trouxe a possibilidade de se definir atos que ainda estão por surgir, superando o problema da deficiência enumerativa dos atos de comércio. Isto porque, a antiga teoria excluía diversas atividades econômicas essências à sociedade, ao passo que a teoria da empresa, por sua generalidade, inclui todas as atividades lícitas que se caracterizem como empresa.

\section{DISCUSSÃO}

$\mathrm{Na}$ antiguidade e desde o Código de Napoleão, na França, os atos de comércio eram definidos pelo caráter da mercantilidade, tendo o objeto da ação do sujeito, e não ele como principal agente para a prática desses atos. Desta forma, tanto a legislação da época, quanto a doutrina não enfrentaram a tarefa de definir o comerciante.

Seguindo os passos do Código de Napoleão, o Código Comercial brasileiro também não enfrenta a tarefa da definição para enquadramento da mercancia, definindo apenas o sujeito e não os atos, conforme preceituava o do artigo art. 4ํ do Código brasileiro.

Art. 4ㅇ․ Ninguém é reputado comerciante para efeito de gozar da proteção que este Código liberaliza em favor do comércio, sem que se tenha matriculado em algum dos Tribunais do Comércio do Império e faça da mercancia profissão habitual.

Rapidamente, à primeira vista, tal silêncio poder-se-ia ter-se mostrado uma evolução. Contudo, continuava a indagação do que seria mercancia. Para defini-la, surgiu o Regulamento no 737 de 1850, visando além de esclarecer a mercancia, determinar a competência dos Tribunais do Comércio.

Art. 19. Considera-se mercancia:

$\S 1$ 10 A compra e venda ou troca de effeitos moveis ou semoventes para os vender por grosso ou a retalho, na mesma especie ou manufacturados, ou para alugar o seu uso.

$\S 2$ ㅇ As operações de cambio, banco e corretagem.

$\S 3^{\circ}$ As emprezas de fabricas; de com missões; de depositos ; de expedição, consignação e transporte de mercadorias; de espectaculos publicos. (Vide Decreto $\mathrm{n}$ - 1.102, de 1903) 
$\S 4 .^{\circ}$ Os seguros, fretamentos, risco, e quaesquer contratos relativos ao cornmercio maritimo.

$\S 5 .^{\circ}$ A armação e expedição de navios.

Observa-se, pois, que o art. 19 do referido Regulamento enumera os atos de comércio.

Segundo Rocco (2003, p.196), a partir dos vários problemas interpretativos, surgidos desde 1807 na França, a doutrina e a jurisprudência entenderam que a enumeração é exemplificativa, comportando extensão por analogia, desde que esses outros atos apresentassem de fato certas analogias.

Observando-se o silêncio do sistema do Código de 1850, e o Regulamento 737, notam-se dois aspectos, um subjetivo por assentar-se na figura do comerciante, e ao mesmo tempo objetivo, por apresentar enumeração legal dos atos de comércio, esclarecendo o que seja mercancia.

De acordo com Requião (2008, p.45), após várias divergências doutrinárias, a classificação foi reduzida a atos objetivos e atos subjetivos, de forma simples e didática, dando azo aos atos de comércio acessórios, como decorrência da teoria do acessório, ou seja, o acessório segue o principal.

Então, são atos, que mesmo não sendo comerciais, são praticados por sujeito na condição de comerciante, por isso eram denominados de aos de comércio acessório, por conexão ou dependência.

Com essa extensão, surgiram problemas, no Brasil, quanto a competência dos atos comerciais e civis. Para tentar por uma pá de cal sobre a controvérsia, foram instalados os Tribunais de Comércio, extintos depois, em 1875, pelo Decreto Imperial № 2662, dando lugar à instalação da unidade do direito processual brasileiro.

Aparentemente, não havia mais problemas de competência, despontando o seguinte questionamento: qual o interesse em estudar os atos de comércio? A resposta estava na insuficiência destes, o que levaria a uma evolução da teoria dos atos de comércio para a teoria da empresa.

Como observou Vieira (1960), as forças e instituições econômicas sempre influenciaram profundamente a estrutura e evolução da sociedade. Na modernidade, com a revolução da ciência, da técnica e da tecnologia, os bens econômicos passam a ser de novos tipos e altamente reprodutíveis e determinantes das relações sociais. Com isto, as influências e instituições econômicas ganharam força, agindo diretamente, por duas vezes, no Direito Comercial, modificando-o e renovando-o de acordo com as necessidades impostas pela economia na 
estrutura e evolução da sociedade, agindo primeiramente para formar os atos de comércio e em seguida, quando se tornou urgente uma nova teoria, a teoria da empresa.

Como assevera Ulhoa (2014, p. 27-8), na lista de atos de comércio, na França, não se encontravam diversas atividades econômicas que foram ganhando a mesma importância do comércio, banco, seguro e indústria, tais como: prestação de serviços (diretamente relacionada à urbanização); as atividades econômicas relacionados à terra, que não constavam nas listas por causa da ideologia dominante da burguesia contra os ex-senhores feudais, dentre outras.

Diante da insuficiência declarada da teoria dos atos de comércio, surgiu, em 1942, na Itália, a teoria das empresas visando delimitar o campo de incidência do Direito Comercial no âmbito das relações econômicas entre particulares.

Por meio da nova teoria as atividades ligadas à terra e a prestação de serviços passaram a se submeter às mesmas normas aplicáveis às comerciais, bancárias, securitárias e industriais.

Para Ulhoa (2007, p. 18) "não se supera, totalmente, um certo tratamento diferenciado das atividades econômicas", pois de acordo com o vulto das atividades econômicas, o Direito Comercial acabou tratando de forma diferente os empresários.

O Direito Brasileiro, na esteira do Código Civil de 2002, adotou completamente a teoria da empresa e revogou a primeira parte do Código Comercial de 1850. Nesse passo observa-se uma unificação, quase total do Direito Civil e Comercial. A evolução brasileira, contudo, veio apoiada desde na jurisprudência, com juízes concedendo concordata ${ }^{1}$ a pecuaristas; decretando a falência de negociantes de imóveis; assegurando a renovação compulsória do contrato em favor dos prestadores de serviços; julgando, enfim, as demandas com base nos critérios da empresalidade.

Consoante assevera Ulhoa (2007, p.26), há ainda exemplos de leis que seguiram a nova teoria, tais como o Código de Defesa do Consumidor de 1990, a Lei de Locação Predial Urbana de 1991 e a Lei do Registro de Empresas de 1994. No entanto, o coroamento ocorreu com o Código Civil de 2002, protegendo juridicamente todo empresário, não precisando sua atividade econômica estar prevista expressamente em lei.

Assim, a atividade empresarial, no ordenamento brasileiro, deve enquadrar-se no art. 966 do Código Civil, que assim preceitua:

Art. 966. Considera-se empresário quem exerce profissionalmente atividade econômica organizada para a produção ou a circulação de bens ou de serviços. Parágrafo único. Não se considera empresário quem exerce profissão intelectual, de natureza científica, literária ou artística, ainda com o concurso de auxiliares ou colaboradores, salvo se o exercício da profissão constituir elemento da empresa.

\footnotetext{
${ }^{1}$ Com a nova Lei de Falências, em 2005, a concordata deixou de existir, dando lugar ao instituto da Recuperação judicial e extrajudicial de empresas. 
Observa-se, então, que a partir do Código Civil de 2002, passam a ser exigidos três requisitos para a caracterização do empresário: profissionalismo (habitualidade e pessoalidade), atividade econômica organizada, e produção ou circulação de bens ou serviços. (ULHOA, 2014, p.31)

Observa-se que os atos os requisitos para os atos de mercancia encontram-se inseridos no contexto da definição do empresário, a habitualidade no contexto do profissionalismo, a pretensão lucrativa no bojo da atividade econômica organizada e, por fim, a intermediação inserta na produção ou circulação de bens ou serviços.

Com tudo isso, é oportuno observar que o direito pátrio não definiu a empresa, já que o Código Civil, no artigo 966, apenas caracteriza a figura do empresário, como aquele que exerce profissionalmente atividade econômica organizada para a produção ou a circulação de bens ou de serviços.

Há grande confusão semântica quanto à palavra empresa, que é levada à figura do estabelecimento.

Para Requião (2008, p. 59) a empresa é uma ficção da lei e quando relacionada ao estabelecimento, é algo real e material e não deixa de ser uma entidade jurídica, uma abstração. Isto porque o empresário é o unificador dos bens e da pessoa, já que ambos não se juntam. Desta forma, a empresa nasce apenas quando surge a atividade sob a orientação do empresário, momento em que se faz necessário o exercício da atividade profissional produtiva de produção ou circulação de bens ou serviços. É neste momento que nasce a figura do empresário.

Decorrente da teoria da empresa, esta é, atualmente, o resultado da atividade econômica organizada e está influenciada pelo capitalismo, sem perder o foco da função social que deverá ser exercida pela empresa.

A generalidade do conceito mostra-se necessária no capitalismo atual, pois o desenvolvimento tecnológico e de serviços cria novas atividades econômicas todos os dias, atividades que seriam impossíveis de serem previamente enumeradas pelos critérios dos atos de comércio.

\section{CONCLUSÃO}

Desde o Código Napoleônico de 1804, as definições dos atos de comércio passaram por grades transformações para adequarem-se à realidade mercantil. Transformações, todavia, mais lentas que a evolução natural do comércio, fato que levou ao surgimento da teoria da empresa 
(um conceito mais amplo) na Itália em 1942, posteriormente adotada pelo Brasil, com o advento do Código Civil de 2002.

A figura da mercancia, sempre taxativa nos códigos, excluía diversas atividades econômicas. Se a lei não caminhava no mesmo ritmo do comércio, este também se atrasava. $A$ questão se tornou mais acentuada quando surgiu a necessidade de separar atos civis e comerciais, a fim de identificar a figura do comerciante. A Doutrina Italiana apresentou a sua contribuição com a criação da teoria da empresa, e o Código Civil brasileiro de 2002 aderiu ao critério de identificação do empresário, no seu art. 966, em que pese não ter havido a definição de empresa.

A teoria da empresa define atos que ainda estão por surgir, de modo a superar o problema da deficiência enumerativa dos atos de comércio. Enquanto a antiga teoria excluía diversas atividades econômicas essências à sociedade; a teoria da empresa, por sua generalidade, inclui todas as atividades lícitas que se caracterizem como empresa.

\section{REFERÊNCIAS}

BERTOLDI, Marcelo M.; RIBEIRO, Marcia Carla Pereira. Curso Avançado de Direito Comercial. 6.ed. São Paulo: Revista dos Tribunais, 2011.

COELHO, Fábio Ulhoa. Curso de direito comercial: direito de empresa - volume I. 11ạed. São Paulo: Saraiva. 2007.

Saraiva. 2014

. Manual de Direito Comercial: Direito de Empresa. 26ạed. São Paulo:

DORIA, Dylson. Curso de Direito Comercial. 13.ed. São Paulo: Saraiva, 1998.

GOMES, Fábio Bellote. Manual de Direito Comercial: de acordo com a nova lei de falência e recuperação de empresas. 2.ed. São Paulo: Manole, 2007.

GONÇALVES, M. G. V. P. R.; GONÇALVES, V. E. R. Direito Comercial: direito de empresa e sociedades empresárias. 3.ed. São Paulo: Saraiva, 2010.

JUNIOR, W. F. Manual de Direito Comercial. 13.ed. São Paulo: Atlas, 2012.

MARTINS, F. Curso de Direito Comercial: empresa comercial; empresários individuais; microempresas; sociedades empresárias; fundo de comércio. 34.ed. Rio de Janeiro: Forense, 2011.

NEGRÃO, Ricardo. Manual de Direito Comercial e de empresa: teoria geral da empresa e direito societário. Vol. 1. 9.ed. São Paulo: Saraiva, 2012.

REQUIÃO, Rubens. Curso de Direito Comercial, 1ำ volume. 27ạed. São Paulo: Saraiva, 2007. 
ROCCO, Alfredo. Princípios de Direito Comercial. Tradução por Ricardo Rodrigues Gama. 1aed. Campinas/SP : LZN, 2003.

VIEIRA, Dorival Teixeira. Economia e sociedade, panorama da ciência econômica contemporânea. São Paulo: Companhia Editora Nacional. 1960. 